\title{
Evaluation Indexes Design for Sustainability Development of a Country Based on the Intelligent Systems
}

\author{
Nianji Tang \\ School of North China Electric Power University, Baoding 071000, China \\ 1500430027@qq.com
}

Keywords: AHP; intelligent systems; sustainability development evaluation.

\begin{abstract}
Our paper provide select human health, food security, equitable sustainable development, local environmental quality, and energy access, livelihoods, community vulnerability, and access to clean water as indexes to evaluate whether a country is sustainable. With the research of the Intelligent Systems Analytic, we can clearly define when and how a county is sustainable or unsustainable and obtain countries that need the most support and intervention. Finally we obtain the solution of AHP.
\end{abstract}

\section{Introduction of the Background of This Creativity}

Sustainable development is defined by the 1987 Brundtland Report as "development that meets the needs of the present without compromising the ability of future generations to meet their own needs."

The United Nations (UN) predicts the world's population will level at 9 billion people by 2050 . This, coupled with increased consumption, places a significant strain on the earth's finite resources. International aid agencies, planners, governments, and non-profit organizations are committed to construct an evaluation system for sustainable development. Therefore, striving towards a sustainable future has never been more imperative.

\section{The definition of Evaluation Indexes and Data processing}

According to the definition of sustainable development and the principle of evaluation indexes, we finally select eight indexes to develop an evaluation system, which are contains health human, food security, access to clean water, local environmental quality, energy access, livelihoods, community vulnerability, and equitable sustainable development.

\subsection{Human Health}

The damaging effects of human impacts on natural environment have had a serious health threat on human beings themselves, and become an important factor in economic and social sustainable development [1]. So we select health expenditure per capita, improved sanitation facilities (\% of population with access) and life expectancy at birth, total (years) by Principal Component Analysis method, which cumulative contribution rate more than $80 \%$. Let hh denote the index of human health:

$$
h h=h e+s f+l e
$$

Where he denotes the index of health expenditure per capita for i year, sf denotes the index of improved sanitation facilities (\% of population with access) for i year and le denotes the index of Alternative and life expectancy at birth, total (years) for i year.

\subsection{Food Security}

Food is an essential subsistence substance for human survival and development, which is closely related to the life and health of the people. If food security cannot be guaranteed, it will threaten human survival and development and affect the sustainable development of human society and economic. According to the data from the World Bank Group, we use Global food safety index to measure food security of a country.

$$
f_{s}=g f
$$


Where fs denotes food security of a country for i year, and gf denote Global food safety index for i year.

\subsection{Access to Clean Water}

As the rapid increase in global population and per capita income levels, global clean water scarcity is emerging. The condition access to water is an important part that reflects the sustainability degree of a country. Therefore, we apply Principal Component Analysis method and collect data that contains improved water source, rural (\% of urban population with access) and improved water source, urban (\% of urban population with access) from World Bank Group. Let w denote the index of accessing to clean water:

$w=r+u$

Where $r$ denotes improved water source in rural areas for i year, and $u$ denotes improved water source in urban areas for i year.

\subsection{Local Environmental Quality}

The development of economic and social shouldn't exceed the load capacity of the resources and the environment. Sustainable development is based on the natural resources and coordinate with the environment. Sustainable development requires that economic construction is carried out under sustainable use of resources and the protection of the environment conditions, to ensure the sustainable use of natural resources. Human development is controlled within the load capacity of the Earth. Therefore, we take local environmental quality into account when develop an evaluation system.

After applying Principal Component Analysis method to many environmental indexes from World Bank Group, we select Forest area (\% of land area) and emissions (kt), which cumulative contribution rate more than $80 \%$. Let e denote the index of Local environmental quality:

$$
e=f+c
$$

Where $\mathrm{f}$ denotes the indexes of Forest area (\% of land area) for i year, and c denotes the indexes of $\mathrm{CO} 2$ emissions $(\mathrm{kt})$ for i year.

\subsection{Energy Access}

Energy resources is an important material basis for social and economic development, and sustainable use of energy resources is the key to achieving sustainable development. Energy use promotes economic growth and social progress in certain extent, but the long-term unreasonable use of energy have had a negative impact on the environment and resources, so the extent of energy use, the patterns of energy and other issues has become one of the core issues of sustainable development concerns.

We use Principal Component Analysis method to many energy access indexes from World Bank Group, then select GDP per unit of energy use, combustible renewables and waste (\% of total energy) and Alternative and nuclear energy ( $\%$ of total energy use), which cumulative contribution rate more than $80 \%$. Let a denote the index of energy access:

$$
a=2 * e u+r w+n e
$$

Where eu denotes the indexes of GDP per unit of energy use for i year, rw denotes the indexes of combustible renewables and waste (\% of total energy) for i year and ne denotes Alternative and nuclear energy ( $\%$ of total energy use) for i year.

\subsection{Livelihoods}

Sustainable Development noted that the development stage of the world may be different and the development of specific objectives vary, but the essence of development should include improving livelihoods of people.

To describe the level of livelihoods, we select three indexes that include Poverty headcount ratio at $\$ 1.25$ a day (PPP) (\% of population),Unemployment, total (\% of total labor force) and Employment in agriculture ( $\%$ of total employment), Let 1 denote the level of livelihoods, then it could be calculated as follows

$$
l=2 * h p+u p+e a
$$


In which hp stands for Poverty headcount ratio at $\$ 1.25$ a day (PPP) (\% of population), up stands for Unemployment, total (\% of total labor force) and ea stands for Employment in agriculture (\% of total employment).

\subsection{Community Vulnerability}

Community vulnerability is a nature, which the buildings and the crowd in the community show the ease of hurt and loss when facing a specific disaster. We use Incidence of tuberculosis (per 100,000 people) tc and Prevalence of HIV, total (\% of population ages 15-49) hv to stand for the index of community vulnerability v.

$v=h v+t c$

\subsection{8 Equitable Sustainable Development}

Sustainable development attach importance to the eradication of poverty. It try to give all countries and regions of the people, generations of people with an equal right to development.

We use income share held by lowest $20 \% \mathrm{lw}$, Income share held by highest $20 \% \mathrm{hg}$ and Ecological footprint ef to express equitable sustainable development es:

$e s=l w+h g+0.5 * e f$

\section{Conclusion}

The final destination of our model, is to lay the good foundation to find the most suitable pattern for the sustainable development of a country. With the research of the Intelligent Systems Analytic, we can clearly define when and how a county is sustainable or unsustainable and obtain countries that need the most support and intervention. Finally we obtain the solution of AHP. We can clearly define when and how a county is sustainable or unsustainable. We can also obtain countries that need the most support and intervention.

\section{Reference}

[1] Yang Zhousheng. Environment and Human health [M].Anhui Normal University Press, 2011.

[2] Deng Xue, Li Jiaming, Zeng Haojian. Research on Calculation Methods of AHP Weight Vector and Its Application [J]. Mathematics in practice and theory, 2012, 07:93-100.

[3] J. van der Geer, J.A.J. Hanraads, R.A. Lupton, The art of writing a scientific article, J. Sci. Commun. 163 (2000) 51-59.

[4] Reference to a book: W. Strunk Jr., E.B. White, The Elements of Style, third ed., Macmillan, New York, 1979.

[5] Reference to a chapter in an edited book: G.R. Mettam, L.B. Adams, How to prepare an electronic version of your article, in: B.S. Jones, R.Z. Smith (Eds.), Introduction to the Electronic Age, E-Publishing Inc., New York, 1999, pp. 281-304.

[6] R.J. Ong, J.T. Dawley and P.G. Clem: submitted to Journal of Materials Research (2003)

[7] P.G. Clem, M. Rodriguez, J.A. Voigt and C.S. Ashley, U.S. Patent 6,231,666. (2001)

[8] Information on http://www.weld.labs.gov.cn 